\title{
An analysis of power supply design in networking systems on the practices of supply chain management
}

\author{
Ramesh Chandra Rath ${ }^{1}$, Nihar Ranjan Hota ${ }^{2}$, Himanshu Shekhar Maharana ${ }^{3}$, Sunil Kumar Patel ${ }^{4}$ \\ ${ }^{1}$ Professor in Management Dept. of Basic Sci. \& Humanities \\ ${ }^{2}$ Assistant Professor, Department of Computer Science \&Engineering. \\ ${ }^{3}$ Assistant Professor, Department of Electrical Engineering \\ ${ }^{4}$ Assistant Professor in Dept.of Computer Science Engineering \\ Einstein Academy of Technology \& Management (EATM), Bhubaneswar (India) \\ Approved by AICTE \& Affiliated to Biju Patnaik University and Technology (BPUT) Rourkela, Odisha (India)
}

Email address:

ramesh.ch.rath@gmail.com (R. C. Rath), nihar.btech.mba.mtech@gmail.com (N. R. Hota), hsmaharana@gmail.com (H. S. Maharana), tosunilcse@gmail.com (S. K. Patel)

\section{To cite this article:}

Ramesh Chandra Rath, Nihar Ranjan Hota, Himanshu Shekhar Maharana, Sunil Kumar Patel. An Analysis of Power Supply Design in Networking Systems on the Practices of Supply Chain Management. International Journal of Business and Economics Research. Special Issue: Supply Chain Management: Its Theory and Applications. Vol. 3, No. 6-1, 2014, pp. 81-86. doi: 10.11648/j.ijber.s.2014030601.22

\begin{abstract}
Now-a-days power supply and its networking system play a first and foremost role in every aspects of human life as well as organizational life. This invited article analyzes about "An offline, three-output, 150-W forward converter is used as an example to illustrate the design process for typical isolated converters. This example emphasizes the basics with a doubleended forward topology using coupled inductors for output accuracy. Design issues and trade-off decisions to optimize power efficiency while keeping costs to a minimum are highlighted. Finally, the presentation of measured performance results confirms the design process." Electrical power is the rate of movement of electrons that create energy. As a result of the electronic age many products need electrical power to perform certain activities. Being able to manipulate electrical power comes at a cost. In today's world there is always the bottom line, cost Power supplies are the devices that can manipulate electrical power to be used in various applications. Power supplies can be expensive but there are cheaper alternative solutions that can produce the same output. A power supply includes conversion steps and has to be reliable enough not to damage what it is hooked up to. Both aspects need specific parts in a certain orientations to create those specific outputs. Throughout this note there where is much suggestion on how to create a cheap reliable power supply.
\end{abstract}

Keywords: Power Supply Design (PSD) Net-Working System (NS) Supply-Chain Management (SCM), Design Process (DP), Typical Isolated Converter (TIC), Cheap -Reliable Power -Supply (CRPS), TP-Topology

\section{Introduction}

Power is used in everyday life. Ever since the basic ideas of power were thought up by Nikola Tesla and others, then implemented in today's power system, people have been craving power. People need power to run their homes, cars, computers, etc. To be able to manipulate power is vital to today's society. Power is defined as "Voltage or Current" which proceeds in a continuous plow of current supply. The current within this equation comes in two flavors AC and DC. Every circuit designed today needs power to be applied for the circuit to function. DC is the basis for most circuit designs that goes into everyday products. If a circuit has no power a circuit would not be able to perform its desired function. A variable DC power supply, seen in every electronics lab, on the market today costs around $\$ 300$. These lab power supplies are very good for testing a circuit in the lab but not useful to be used in a product application. These power supplies can be very bulky and not very mobile. There is a need for a power supply that is cheap, reliable, efficient, and small if the practices of supply chain management are effective in its Power supply networking.

\subsection{Literature Review}

The authors of the invited article, we have focused in our research work by doing number of experiments upon various 
companies, firms, enterprises, organization's (of India ) power supply networking system (PSNS) as well as supply chain management systems (CMS) how influencing their management systems(MS) in order to consume cheap and low cost transmission of power. Again the SCM as a integrative process of supply chain optimization which is the processing the company's internal practices of interacting with various suppliers (Venders) and customers in order to bring products to market more efficiently in a less time and it is will only possible through the wide range of supply chain management practice through the help of power supply network systems.

The Power supply networking systems (PSNS) has successes, if the concerned organizations or power plant's Energy Resource Planning (ERP)fails because in order to forecast the inventory levels of power. Thus the supply chain management needs ERP's data base co-operation.( Laudon \&Laudon 2002). A powerful supply chain management (SCM) includes the systemization and Optimization of operational and strategic information, the method of net-work adopting in between power supply companies for transmitting $\mathrm{AC}$ to $\mathrm{DC}$ with consuming low cost investment with high cost return of power supply.

The supply chain management (SCM) can be utilize the power supply networking concepts and web technologies to bring the organization in a upstream and downstream and it is a strategic Finally the researchers will hopeful by presenting this research article in to the eyes of intellectuals for their kind perusal and seeking a strong feedback from themselves regarding the above said.

\subsection{Purpose of Research}

Like other researcher, in the concerned article, the researchers have been showing their keen interest to prove the role of power networking system how effective on the practices of supply chain management in order To create a cheap, reliable, and effective DC power supply. There is a basic design that can be adjusted to fit many applications. This supply needs to be small so it can be versatile to be applied in many products on the practices of Supply chain Management.

\subsection{Electric Power Supply System}

Electric power supply system in a country comprises of generating units that produce electricity; high voltage transmission lines that transport electricity over long distances; distribution lines that deliver the electricity to consumers; substations that connect the pieces to each other; and energy control centers to coordinate the operation of the components.

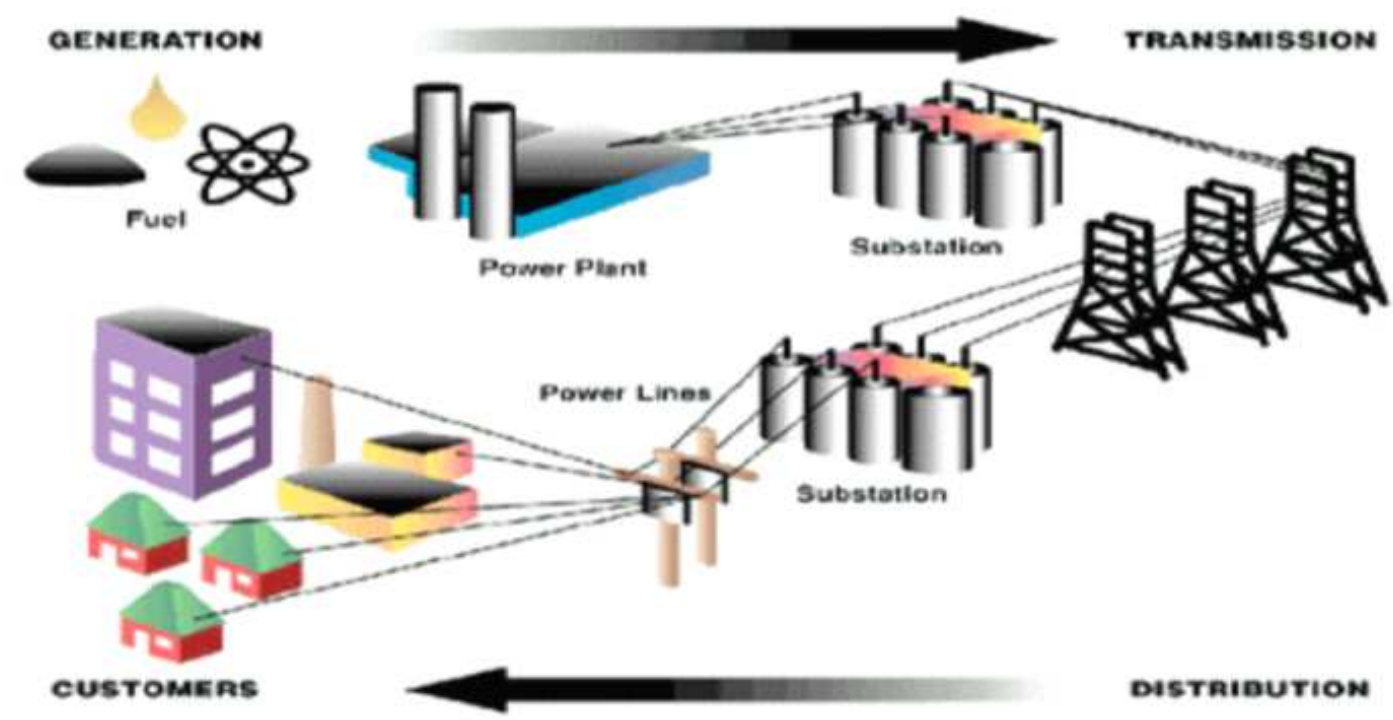

Figure 1. Electric power supply System through SCM

The Figure 1. Shows a simple electric supply system with transmission and distribution network and linkages from electricity sources to end-user. Like from the sources of energy (production) to the door step of consumer through the distribution system (DS) where SCM plays an important role to perform it for a successful distribution.

A power supply is primarily a buffer or interface between a power source and a load, which, without the power supply would be incompatible. It also has to interface with an environment. I like that the paper recognized this by discussing load, power source, safety, EMI, mechanical, and thermal design right at the beginning in the requirements section of the overview.

\subsection{What is Topology?}

As Topology as concerned, it is the part of science of place, refers "as the branch of geometry which indicates about the perfect elastic figures."

\subsection{Network Topology}

In the invited article, the authors has focusing about the 
network topology because it is related with the power supply system, where it refers to the properties that relates to the geometry of the network (Circuit).In which the power system proceeds through the mode of topology.

\subsection{Role of Topology in Power Supply}

It facilitates the power supply system of networking with controlling the flow of energy in to a stable pattern of current supply (Low \&High) in to a machine, home appliances etc. Then comes defining the power train consisting of: Topology, Input Configuration, Transformer Design, Voltage-Mode or Current-Mode Control, and Output Filter Design.

The paper throws the control mode (voltage-mode or current-mode control) in the middle of this section, which implies you should mix control in with the power train. My own approach gets the power train working first, and then goes on to design the control. However, no harm done, and in truth, design is an iterative process, not a linear flow. Since you need to sense current for current-mode control and this may affect the power train details, perhaps it does belong here.

What the paper does not do, thank goodness, is to throw everything into a SPICE circuit schematic and hope for the best. I have seen enough new designers do this that I think it is the approach taught in school. Disaster usually awaits those that take the SPICE total-schematic approach for initial power supply design.

Next the paper describes the detailed design, called the plan of record in the paper. Each topic is filled with the expected design equations, part trade-offs including cost, tables, and figures.

\subsection{Design of Networking}

- The sequence is logical:

- Define Requirements

- Define Topology and Control Method

- Define Input Section

- Transformer Turns Ratio

- Output Inductor

- Output Capacitors

- Output Rectifier Snubbers

- Output Rectifiers

- Power Switch FETs

- IC PWM Controller

- Setting up the Loop

- A Few Optional Ideas

\subsection{Method of Study}

Like other researcher, both the author of this article has followed the guide lines of research work by taking the method of research work such as:

\section{Research Methodology}

(A)Plan \& Procedure:

(B) Research Design:
(C) Data Collection:

(D)Data Presentation:

(E) Data Analysis:

(F) Data Interpretation

\subsection{Hypothesis Testing}

In the current article presented by the researchers, is purely their own and original findings about the title "An analysis of power supply networking design on the practices of supply chain management" has been based on the availed data through the direct survey of the respondents from the various power plant ,supplier, distributer etc. In this article, the researchers have done a full lunch survey of their extensive research work by taking fifty companies of India for their power supply net -work systems on the practice Supply chain Management (SCM). Out of 50 companies 40 companies already adopting power Systems of networking and 10 companies still continue their traditional methods of power supply on the practices of Supply chain management (SCM), despite of the modern power supply networking system develops ,still they have used the traditional method of supply,

In connection with, the researchers were asked 100 consumers, ,10 power supplier, and 50 power plant companies of producing electrical products and home appliances in order to know their response whether they are favor of power supply mode of networking design (Ho) or Traditional Method of power supply (He)? Out of 160 respondents, 120 respondents (Consumer of electricity) are strongly agree 30 respondents are partially agree and 10 respondents are not the support for the implementation of power supply network design on the practices of SCM process . Thus, the researchers have analyzed the data (Both primary data \& Secondary data) as per the data analysis, (I) Data collection (ii) Data presentation (iii) Data Classification (iv) Data analysis (Vi) Data Interpretation . By method of hypothesis testing, the researcher found that the availed data from the respondents stands its validity and authenticity in order to implement on favour of Power supply networking design on practices on supply chain management system in each and every power plant whenever they supply power or energy to customer or any product, machine, home appliances Thus, the result proves that its significance \&Ho (Null hypothesis has been accepted due to its authenticity than the $\mathrm{He}$ (alternative hypothesis). Here, findings of respondent's views are graphically present for reader's kind perusal \&perception.

Early as the research work, the respondents had response Ok, well and good. But how do experienced power supply designers really design? Some continue to do it as in the paper, but the process gets modified over time as it is influenced by company policies, the designer's preferences, and other constraints.

We define a good designer as one whose designs go into the field and meet their performance requirements and don't fail, even in abnormal use. After performance requirements are met, field reliability rules. No two designers have the 
same approach.

One designer I knew who met these criteria started with a drawer filled with schematics that had been proved reliable in the field. When assigned a circuit, he found the closest schematic, had a breadboard built, modified the breadboard until it met the performance requirements, and then did the most complete and prolonged testing of it I ever witnessed. (Those that start with vendor reference designs follow a similar path, although the design usually has not been proved reliable in the field.) His designs did not fail in the field.

How did he come by this approach? He came from a company who first gave the design to one engineer and when he was finished, gave the laboratory notebook, schematic and breadboard to a second engineer to perform a design review. If the circuit proved itself in the field, both got credit, if it failed in the field, the reviewer could expect a period of poor performance reports and no raises. Strong motivation to make sure your fellow engineer's circuit worked. Their approach was logical in his initial design environment and worked very well in other design environments.

Our own approach was formed by a design environment where my power supplies had to go into a computer on circuit boards the same form factor as the logic boards, which changed form factor and slot pitch for each computer. The only variable was how many logic slots the power supply occupied. You could not get a power supply in a single logic board slot, but keeping the slots used to the minimum was critical. The capacitor tubes controlled the minimum slot consumption and their diameter in turn determined the maximum height of the magnetic could take without increasing the number of slots taken by the power supply.

We started each design with a tool kit of balsa wood, wooden dowels, and other modeling material and tools that let me mechanically do the layout of the number of capacitor tubes and magnetic. The envelope of the maximum magnetic height controlled the cores that could be used. The power train was laid out on the board like a jig saw puzzle. Then a design was created that fit the layout. Later I replaced the tool kit with a desk top PC CAD program. The input EMI filter was designed and laid out first (since doing it last often resulted in an EMI filter bigger than the rest of the power supply). Then the Middle brook Criteria was used to fit and design the output filter. The rest of the design was then juggled to make everything else work. This unusual design method worked, producing designs that beat the best watts/per/cubic-inch state-of-the-art at the time.

Other designers start with equations and solve the equations with circuit elements and many uses an approach similar to that in the paper. The point is that you need a starting point such as a reference design, a previous design you have done, or a design procedure as given in the paper. With experience, you will develop your own methods. In my experience, no two experienced designers reach the goal of performance with field reliability in the same way. What counts is not how you reach it but that you reach it in a way that works efficiently for you. But you have to start some place, and papers like this serve the need.

\subsection{Design a Simple DC Power Supply}

The power that comes into the house travels, sometimes, hundreds of miles to get there .Through this processes AC current is used. AC or alternating current has different phases depending on the application. These phases are created by the physical offset of the original power generator. In contrast to $\mathrm{AC}$ there is DC or direct current. DC doesn't alternate the current; it outputs a steady current to be applied to circuits. $\mathrm{DC}$ is useful in circuit design because many of the components do not function well if an $\mathrm{AC}$ is applied. $\mathrm{AC}$ is the current that is brought to a normal house wall socket. Through the wall socket many different devices are plugged in and used every day but most of these devices need DC to operate correctly. When a plug is inserted into a wall socket there is an $\mathrm{AC}$ to $\mathrm{DC}$ conversion that takes place. This is commonly done by using a full-wave rectifier. The full wave rectifier in figure 1 allows an input of $\mathrm{AC}$ and creates a small ripple current, seen in figure 2 , which is close enough to a DC representation.

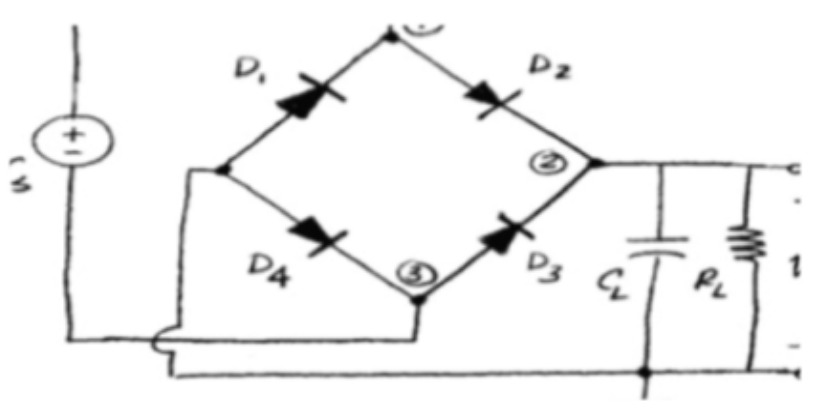

Figure 2. Full- Wave Rectifier.

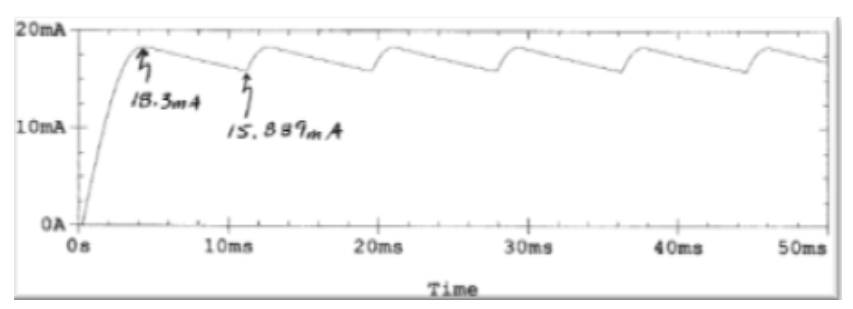

Figure 3. Current across load.

This is a result from the orientation of the diodes. As the voltage changes polarity different diodes are tuned off and on creating the ripple affect seen across the load which can be seen in figure 3 . The concept of AC is very important to building a power supply because the main source of power in a home is AC. The conversion method shown in figure 2 is the method that will be applied to the cost effective power supply.

\subsection{Linear Regulators}

Once a ripple output is established from the Full wave rectifier a stable voltage needs to be created. A stable voltage is needed for consistent operation from the connected circuit. The cheapest and most cost effective way is to use a linear regulator. A regulator does exactly what the name says, it 
regulates the voltage. Using the voltage input a regulator generates an internal voltage for the regulator to compare the output to be able to hold the output constant. There are two types of regulators fixed and variable. A fixed regulator is set internally to output a specific voltage, $+5 \mathrm{~V},-12 \mathrm{~V}$ etc. A variable regulator can be set to a wide range of voltages. This is done by constructing a resistance divider at the output and varying one resister to obtain the desired DC output. Therefore a variable regulator is very useful if the voltage need to be varied. This can be seen below in figure 4 . The regulator that was chosen was the LM317. This regulator can take in a voltage as high as $+40 \mathrm{~V}$ and as low as $+3 \mathrm{~V}$. The value of voltage would correspond to what voltage level was needed at the output.

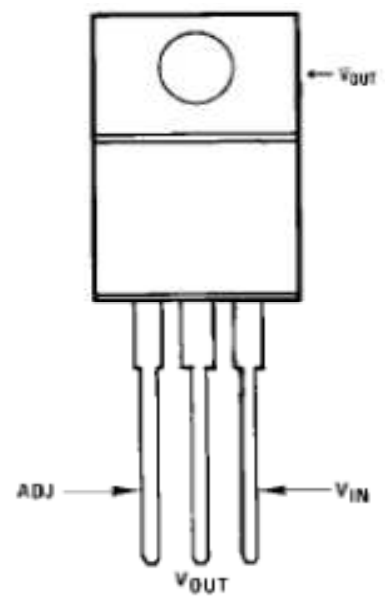

Figure 4. LM317 Application.

For example if an application needed $+5 \mathrm{~V},+10 \mathrm{~V}$ would be needed at VIN to compensate for heat losses and voltage drops that go on within the regulator.

For example if an application needed $+5 \mathrm{~V},+10 \mathrm{~V}$ would be needed at VIN to compensate for heat losses and voltage drops that go on within the regulator.

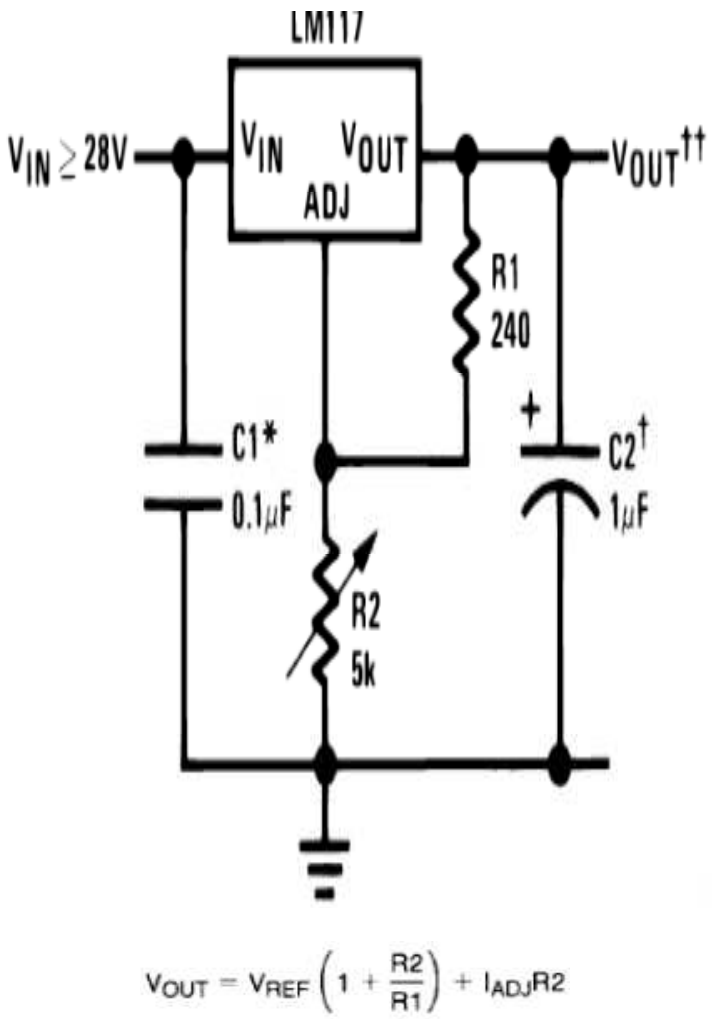

Figure 5. Equation for output voltage.

In figure 5 the equation can be used to create the desired output voltage that is needed for a specific application in power supply design of current $\mathrm{AC}$ to $\mathrm{DC}$ conversion through the supply chain networking systems of management where everything within the equation is kept constant except R2. The other values are constants given as: Vref $=1.25 \mathrm{~V}, \mathrm{R} 1=$ $240 \Omega$, Iadj $=50-100 \mu \mathrm{A}$. Lastly, R2 can be either raised to create a larger output voltage or lowered to create a lower output voltage .Using this regulator helps to obtain a constant output voltage that can be obtained at a low cost.

\subsection{Final Design}

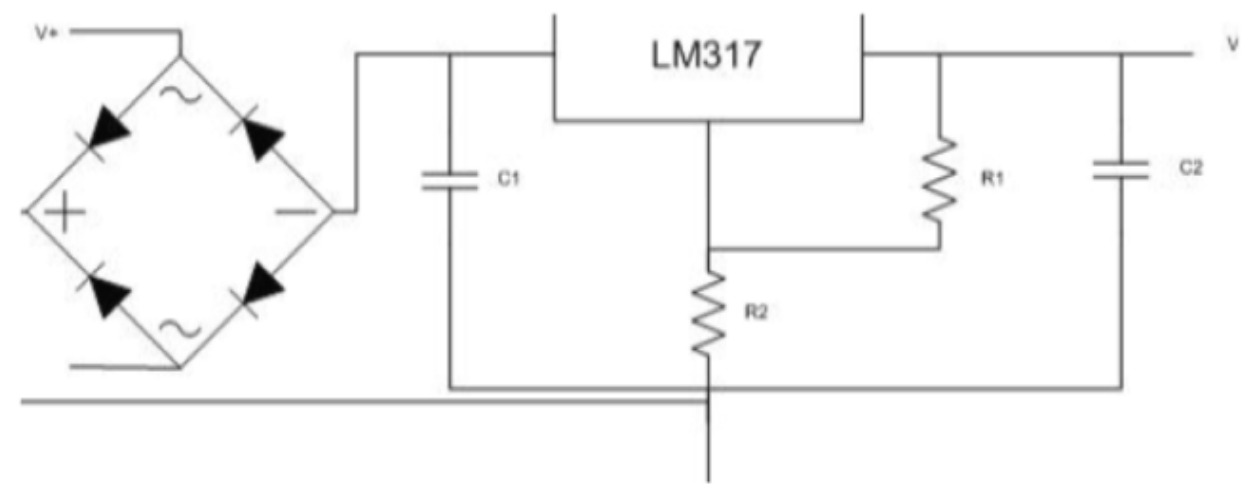

Figure: 6 Final Designs

The complete DC power supply design in figure 6 combines the full wave rectifier and the LM317 regulator. This design is simple and is low cost. The main problem is that it is not very efficient. This set up would not be good in a battery application but if the application can be plugged into the wall this set up can save a lot of money. The total cost is around $\$ 3.00$. This design takes the power from the wall, which has AC. Then using a regulator takes ripple current 
from the rectifier and outputs a constant DC output. This DC output is very useful to power microchips and different ICs.

\subsection{Recommendation \& Suggestion}

After completion of this research article, we want to share our experience with our valuable reader, viewer, intellectual for a broad spectrum of discussion and comments regarding it further development .But during our research work what we smell that we are suggesting something for the upcoming young researchers in the country \& abroad in order to fragrance themselves intellectual budding mind for its further development i.e.

- Please be having confidence upon yourself with your related research work.

- Make sure whether your research is proceeding in a right track or not as per research guide line.

- This research design proves that power supply is so much cheaper in economic and less time for transmission from the place of power plant to customer due to regular using of regulator for controlling ripple current.

- Using regular regulator is so useful and takes ripple current from the rectifier AC (input) to out puts a constant DC.

- DC output is very much useful in power microchips with economic save.

- Power design is very simple for use and preventative and low cost.

- Power networking design is acts with a chaining process by the practices of supply chain management system.

\section{Conclusion}

In sum, the above summations are summarizing that the power supply networking system has been designed in a systematic manner on the basement of practices of supply chain management for providing a good alternative than a more expensive power supply network. By the way, power supply has few components which covers a small area, and it is very simple in design for easily use by companies, customers, for a better, reliable and cheaper consumption of power supply in every aspects of human life.

\section{Acknowledgement}

To completion of the invited task, the researchers have feeling quite comfortable, and the source of comfortable are apart from the blessings of their beloved parents, relatives and well-wishers, faculty members of EATM College as well as apart from their beloved students for their encouragement $\&$ inspiration to write. That's why we have tendered our hearty gratitude to them. Especially my co-authors Er. Nihar Ranjan Hota and Er. Himanshu Shekhar Maharana \& Er.Sunil Kumar Patel. They have dedicated to this article for their lovely Mothers because of their love \& affection encouraged them and motivated to write this article successfully.

Besides above that we have also thankful to Prof. (Dr.) Md. Mamun Habbib, Editor-in chief of IJSCM, London for his kind co-operation and active guidance to us from time-totime in order to complete this research article .Finally, the authors are also thankful to each and every readers, intellectuals, research scholars if they give some valuable feed-back with evaluating both ends of their sharp perception with comment for the further development of research work.

\section{References}

[1] Nar Simhan, R. "An analytic approach to supplier, Selection, J.Purch. Supply Management, 1983, 1, 27, 32.

[2] "Dc Power Supply." Test Equity. 2 Apr.2009 $<$ http://www.testequity.com/ categories/ DC+Power+Supply/>.

[3] "Linear regulator." Wikipedia. Feb. 2009. 2 Apr. 2009 $<$ http://en.wikipedia.org/ wiki/ linear regulator>.

[4] “LM317 - 3-Terminal Adjustable Regulator." National Semiconductor. Apr. 2009. 2 Apr. 2009 $<$ http://www.national.com/ mpf/ LM/ LM317.html>.

[5] “TESLA: Life and Legacy.” PBS. TESSCO. 1 Apr. 2009 $<$ http://www.pbs.org/ tesla/ ll/ index.html $>$.

[6] Wierzba, Gregory. "Diode Characteristic and Circuits." ECE302. EGR Building. Mar. 2007.

[7] Walker, Ed, Design Review: A Step-By-Step Approach to AC Line-Powered Converters, Texas Instruments 2004/05 Power Supply Design Seminar, SEM1600, pp. 3-1 to 3-25. 25 pages.

[8] A text book of Network Theory by P.K Satapathy, Chakrabathy of Sultan\& Chand co publishers, New Delhi.2001,

[9] "Supply Chain Management: Concept and Cases" by Rahul .V. Alteker (p-4) Prentice Hull -2005,

[10] Research manual of power plant of NTPC India Ltd., kanhia, Talcher Anugul Odisha 